\title{
Developmental Outcome of Children with Cerebral Palsy after Feeding and Seating Intervention
}

\author{
Md Khairul Bashar ${ }^{1 *}$ \\ Shahed Iqbal ${ }^{2}$ \\ Mahmood Ahmed Chowdhury ${ }^{2}$ \\ Dhananjoy Das ${ }^{3}$ \\ Md lqbal $^{4}$
}

'OSD, DG Health, Mohakali, Dhaka, Bangladesh.

${ }^{2}$ Institute of Child Health

Chattagram Maa-O-Shishu Hospital Medical College

Chittagong, Bangladesh.

${ }^{3}$ Department of Pediatrics

Chattagram Maa-O-Shishu Hospital Medical College

Chittagong, Bangladesh.

${ }^{4}$ Department of Anatomy

Monno Medical College

Dhaka, Bangladesh.
*Correspondence to:

\section{Dr. Md Khairul Bashar}

OSD, DG Health, Mohakhali, Dhaka, Bangladesh. Mobile : +8801913659534

E-mail:dr.sim72@yahoo.com

http://www.banglajol.info/index.php/CMOSHMCJ

\begin{abstract}
Background: Cerebral Palsy (CP) is a diagnostic term used to describe a group of permanent disorders of movement \& posture causing activity limitation that are attributed to non progressive disturbances in the developing fetal or infant brain. The motor disorders are often accompanied by disturbances of sensation, perception, cognition, communication and behavior as well as by epilepsy, secondary musculoskeletal problem and feeding difficulties. Aims: To see the development of a child with cerebral palsy after comprehensive feeding \& seating intervention. To recommend measure for reducing neurodevelopmental problems. To improve mother- child interaction. Methods: This hospital based prospective cross sectional observational study was done in Child Development Center (CDC) of the Department of Pediatrics, Chattagram Maa Shishu-O-Genaeral Hospital (CMSOGH), Chittagong from July 2013 to December 2013. Children with Cerebral palsy aged 1-15 years included in this study. Results: Most of the patients (60\%) before intervention were having only liquid food. After intervention most of the patients were having either a combination of semi-solid and solid food (48\%) or only semi-solid food (42\%). After intervention $80 \%$ of patients were sitting during feeds which was only $12 \%$ before intervention. After intervention feeding time is reduced to 15 to 30 minutes which was $30 \mathrm{~min}$ to one hour. Most of the patients $(90 \%)$ never ate by themselves before intervention, only $4 \%$ were selffed. After intervention $56 \%$ were self feeding for some part of the meal \& $24 \%$ were self feeding at every meal. Conclusion: Feeding problems in children with cerebral palsy are common. Simple home based measure, like feeding and seating intervention, should be carried out under the guidance of Child Development Center run by developmental therapist with assistance from pediatricians \& child psychologists in order to improve the development of the child with cerebral palsy as well as the quality of life.
\end{abstract}

Key words: Cerebral palsy; Child development center; Feeding problem.

\section{INTRODUCTION}

Cerebral palsy is a well recognized neurodevelopemental condition beginning in early childhood and persisting throughout the life span. Cerebral palsy is a form of chronic motor disability which is non progressive, non fatal \& yet non curable \& results from damage to the growing brain before or during birth, or in postnatal period $^{1}$. The developmental process of a child goes through the period of conception to age 5 years $^{2}$. The period of early childhood development has a strong and positive impact on further development in later stages ${ }^{3}$. Data from UK suggest that feeding difficulties affect between 40 to $90 \%$ of children ${ }^{4}$. Feeding problem may be due to impaired oromotorskills, decreased lip strength, decreased lip mobility, jaw instability, jaw clenching, tongue thrust, tongue retraction, decreased muscle tone and mobility of tongue or decreased muscle tone in cheeks ${ }^{5}$. Gastroesophageal reflux, lack of self feeding skill, impaired expression of hunger or food preference are risk factor for growth abnormalities in children with cerebral palsy ${ }^{6}$. Most children with gastroesophageal reflux experience vomiting and discomfort during feeding and subsequent refusal to feeding? 
Nutritional deficiency of protein, calories, minerals, vitamins \& essential amino acids (especially Lysine) both qualitative \& quantitative, considerably retards physical growth \& development ${ }^{8}$. Dysphagia affects more than $50 \%$ of children with cerebral palsy \& the incidence of dysphagia correlates with severity of motor impairment ${ }^{9}$. It should also be noted that each phase of swallowing is controlled through neural functioning ${ }^{10}$. This study was done among 154 children with cerebral palsy and showed that $26 \%$ of children had oral motor dysfunction and $33 \%$ were unable to self feed and these problems were more prominent in children with severe form of cerebral palsy ${ }^{11}$.

\section{MATERIALS AND METHOD}

This hospital based prospective cross sectional observational study was done in Child Development Center (CDC) of the Department of Paediatrics, Chattagram Maa Shishu-O-Genaeral Hospital (CMSOGH), Chittagong from July 2013 to December 2013. Children with Cerebral palsy aged 1-15 years included in this study. An interview based questionnaire was used to collect information from the mother regarding age, socio-demographic characteristics, educational level of mother, type and amount of food, position during feeding, forced feeding, feeding time, mother-child interaction and child's behavior during feeding, after taking an informed verbal and written consent. The data were analyzed by statistical (SPSS) method and presented in the form of tables, diagram $\&$ charts.

\section{RESULTS}

This study was carried out to see the developmental improvement of the children with cerebral palsy after feeding \& seating interventions. A total of 50 children with cerebral palsy were studied. Age, sex, socio-demographic characteristics of the children, types of cerebral palsy and associated problems, feeding habit, feeding position, time required for feeding and difficulties, self feeding, forced feeding, consistency of food, behavior during feeding $\&$ mother-child interaction before and after intervention were recorded.

Table 1 : Age and sex distribution of the patients $(n=50)$

\begin{tabular}{lrc} 
Age (in years) & Number of patients & Percentage \\
$1-5$ & 40 & 80 \\
$5-10$ & 8 & 16 \\
$10-15$ & 2 & 4 \\
Total & 50 & 100 \\
Sex & & \\
Boys & 28 & 56 \\
Girls & 22 & 44 \\
Total & 50 & 100 \\
\hline
\end{tabular}

$\mathrm{n}=$ Total number of patients

Table 2 : Consistency of food before and after intervention $(n=50)$

\begin{tabular}{lrrrrr} 
Food consistency & \multicolumn{2}{c}{ Pre-Intervention } & & \multicolumn{2}{c}{ Post-Intervention } \\
\cline { 2 - 3 } \cline { 5 - 6 } & no & percentage & & no & percentage \\
Liquid & 30 & 60 & 1 & 2 \\
Semi-solid & 14 & 28 & 21 & 42 \\
Combination of food & 5 & 10 & 24 & 48 \\
Solid & 1 & 2 & 4 & 8 \\
\hline
\end{tabular}

$\mathrm{n}=$ Total no of patients
Table 3 : Feeding time before and after intervention $(\mathrm{n}=50)$

\begin{tabular}{|c|c|c|c|c|}
\hline \multirow[t]{2}{*}{ Feeding time } & \multicolumn{2}{|c|}{ Pre-Intervention } & \multicolumn{2}{|c|}{ Post-Intervention } \\
\hline & $\overline{\text { no }}$ & percentage & $\overline{\text { no }}$ & Percentage \\
\hline 1 hour & 23 & 46 & 1 & $\begin{array}{r}2 \\
(p<0.05)\end{array}$ \\
\hline 30 minute & 24 & 48 & 14 & $\begin{array}{r}28 \\
(\mathrm{p}<0.72)\end{array}$ \\
\hline 15 minute & 3 & 6 & 35 & $\begin{array}{r}70 \\
(p<0.05)\end{array}$ \\
\hline
\end{tabular}

$\mathrm{n}=$ Total no of patients

Table 4 : Self Feeding before and after intervention $(n=50)$

\begin{tabular}{lccrrr} 
Self-feeding & \multicolumn{2}{c}{ Pre-Intervention } & & \multicolumn{2}{c}{ Post-Intervention } \\
\cline { 2 - 4 } Never & 45 & 90 & 10 & $\begin{array}{r}\text { Percentage } \\
\text { no }\end{array}$ \\
During some part of meal & 3 & 6 & 28 & $\begin{array}{r}20 \\
(\mathrm{p}=0.06) \\
56\end{array}$ \\
At every meal & 2 & 4 & 12 & $\begin{array}{r}(\mathrm{p}<0.05) \\
24\end{array}$ \\
& & & & $(\mathrm{p}=0.33)$ \\
\hline
\end{tabular}

$\mathrm{n}=$ Total no of patients

Table 5 : Forced feeding before and after intervention $(n=50)$

\begin{tabular}{|c|c|c|c|c|}
\hline \multirow[t]{2}{*}{ Self-feeding } & \multicolumn{2}{|c|}{ Pre-Intervention } & \multicolumn{2}{|c|}{ Post-Intervention } \\
\hline & $\overline{\text { no }}$ & Percentage & $\overline{\text { no }}$ & Percentage \\
\hline Always & 42 & 84 & 14 & 28 \\
\hline Sometimes & 6 & 12 & 5 & $\begin{array}{l}10 \\
62\end{array}$ \\
\hline Never & 2 & 4 & 31 & \\
\hline
\end{tabular}

$\mathrm{n}=$ Total no of patients

Table 6 : Difficulties in oral motor function before and after intervention $(\mathrm{n}=50)$

\begin{tabular}{|c|c|c|c|c|}
\hline \multirow[t]{2}{*}{ Difficulties } & \multicolumn{2}{|c|}{ Pre-Intervention } & \multicolumn{2}{|c|}{ Post-Intervention } \\
\hline & $\overline{\text { no }}$ & Percentage & $\overline{\text { no }}$ & Percentage \\
\hline Drooling & 40 & 80 & 18 & $\begin{array}{r}36 \\
(p<0.05)\end{array}$ \\
\hline Chewing difficulties & 33 & 66 & 12 & $\begin{array}{r}24 \\
\mathrm{P}(=0.12)\end{array}$ \\
\hline Swallowing difficulties & 28 & 56 & 10 & $\begin{array}{r}20 \\
(p=0.06)\end{array}$ \\
\hline Sucking difficulties & 14 & 28 & 3 & $\begin{array}{r}6 \\
(p<0.05)\end{array}$ \\
\hline Tongue thrusting & 21 & 42 & 5 & $\begin{array}{r}10 \\
(p<0.05)\end{array}$ \\
\hline Mouth open & 27 & 54 & 7 & $\begin{array}{r}14 \\
(p<0.05)\end{array}$ \\
\hline
\end{tabular}

$\mathrm{n}=$ Total no of patients 
Table 7 : Children's behavior during meals before and after intervention $(\mathrm{n}=50)$

\begin{tabular}{lccccc}
$\begin{array}{lcccc}\text { Children's behavior } \\
\text { during meals }\end{array}$ & \multicolumn{2}{c}{ Pre-Intervention } & & \multicolumn{2}{c}{ Post-Intervention } \\
\cline { 5 - 6 } \cline { 5 - 6 } no & Percentage & & Percentage \\
Irritable & 43 & 86 & 18 & 36 \\
Crying & 31 & 62 & 11 & 22 \\
Tantrums & 16 & 32 & 8 & 16 \\
Afraid & 15 & 30 & 2 & 4 \\
\hline
\end{tabular}

$\mathrm{n}=$ Total no of patients

Table 8 : Mother child interaction during meals before and after intervention $(n=50)$

\begin{tabular}{|c|c|c|c|c|}
\hline \multirow{2}{*}{$\begin{array}{l}\text { Mother child interaction } \\
\text { during meals }\end{array}$} & \multicolumn{2}{|c|}{ Pre-Intervention } & \multicolumn{2}{|c|}{ Post-Intervention } \\
\hline & $\overline{\text { no }}$ & $\overline{\text { Percentage }}$ & $\overline{\mathrm{no}}$ & Percentage \\
\hline Poor & 31 & 62 & 4 & $\begin{array}{r}8 \\
(p<0.05)\end{array}$ \\
\hline Some & 12 & 24 & 8 & $\begin{array}{r}16 \\
(p=0.10)\end{array}$ \\
\hline Good & 7 & 14 & 38 & $\begin{array}{r}76 \\
(p<0.05)\end{array}$ \\
\hline
\end{tabular}

Table 9 : Associated morbidities of the children with cerebral palsy $(\mathrm{n}=50)$

\begin{tabular}{lcc}
$\begin{array}{l}\text { Associated } \\
\text { morbidities }\end{array}$ & Number of patients & Percentage \\
Epilepsy & 15 & 30 \\
Visual impairment & 12 & 24 \\
Hearing impairment & 2 & 4 \\
\hline $\mathrm{n}=$ Total no of patients & &
\end{tabular}

\section{DISCUSSION}

Majority $(80 \%)$ of the patients were between ages 1-5 years. Only $16 \%$ were between $5-10$ years and $4 \%$ were between 10 15 years of age. Out of 50 patients $28(56 \%)$ were boys and 22 (44\%) were girls. The study showed $92 \%$ of children with cerebral palsy were in the age group of 1-6 years ${ }^{12}$.

Most of the patients $(60 \%)$ before intervention were having only liquid food. After intervention most of the patients were having either a combination of semi-solid food and solid food (48\%) or only semi-solid food (42\%). Before intervention $2 \%$ were having solid food which increases after intervention (8\%). These study showed before intervention $65.25 \%$ patient were having liquid food. $37.5 \%$ were having semisolid food, $6.25 \%$ were having combination of food. After intervention $6.25 \%$ patient having liquid food. $37.5 \%$ having combination of food and $18.7 \%$ having solid food ${ }^{13}$.

Before intervention most of the patients were being fed in either lying $(60 \%)$ or semi-lying (28\%) position and only $12 \%$ were fed in the sitting position. After intervention $80 \%$ of the patients were sitting during feeds, only 65 were being fed in the lying position and $14 \%$ in the semi-lying position. Another study showed $2 \%$ patients were being fed in lying position, $21 \%$ patients in semi-lying and $77 \%$ patients were being fed in the sitting position ${ }^{14}$.
Before intervention it was taking 30 minutes to being fed 485 of the patients and one hour in $46 \%$ of the patients. In a study prolonged feeding times(3hour/day) was reported by $28 \%$ parents of children with cerebral palsy ${ }^{15}$. After intervention feeding time is significantly reduced to 15 minutes in $70 \%$ $(p<0.05)$ of the patients and to 30 minutes in $28 \%(p=0.72)$ of the patients. Only 1 ( $2 \%$ ) patient was being fed for one hour.

Most of the patients $(90 \%)$ never ate by themselves before intervention. $6 \%$ were self-feeding for some part of the meal and $4 \%$ were self feeding at every meal. After intervention significant improvement were observed. $56 \%(\mathrm{p}=0.33)$ were self feeding at every meal.

Before intervention $84 \%$ patients were being forced fed at all meals and $12 \%$ at some times. After intervention forced feeding were significantly reduced. $28 \%$ patients were being forced fed at all meals. $10 \%$ were never being forced fed.

Before intervention $80 \%$ patients had drooling, 66\% had chewing difficulties, $56 \%$ had swallowing difficulties, $28 \%$ had sucking difficulties, $42 \%$ had tongue thrusting and $54 \%$ had mouth open. After intervention significant improvement were seen in oromotor functions. $36 \%(\mathrm{p}=0.05)$ patients have drooling, 24\% $(\mathrm{p}=0.12)$ have chewing difficulties, $20 \%$ $(p=0.06)$ have swallowing difficulties, 6\% $(p<0.05)$ have sucking difficulties, tongue thrusting and mouth open were present in $10 \%(\mathrm{p}<0.05)$ and $14 \%(\mathrm{p}<0.05)$ of the patients respectively.

Before intervention most of the patients were irritable (86\%), $62 \%$ of the patients were crying, tantrums were present in $32 \%$ and $30 \%$ of the patients were found to be afraid during meals.After intervention children's behavior were significantly improved and irritability present in only $36 \%$, crying in $22 \%$, tantrums in $16 \%$ of the patients and only 2 patients (4\%) were found to be afraid during meals.

Before intervention most $(60 \%)$ of the mother had poor interaction with their children during feeding and $24 \%$ had some interaction. After intervention mother child interaction was significantly improved and $76 \%(\mathrm{p}<0.05)$ mothers have good interaction with their children during meals, $16 \%$ $(p=0.10)$ have some and only $8 \%$ have poor interaction. Out of 50 children with cerebral palsy 29 (58\%) had associated morbidities. $30 \%$ had epilepsy, $24 \%$ had visual impairment and $4 \%$ had hearing impairment.

\section{CONCLUSION}

Feeding problems in children with cerebral palsy are common. Parents should be counseled about the nature of the disease and taught how to handle their child in daily activities especially during meals. Position affects physical, behavioral and communicative participation of a child at mealtimes. A child should be allowed time for sensory exploration like looking, touching, smelling and tasting. Feeding should not be forced as this may restrict food acceptance. Developmental status of a child with cerebral palsy can be improved by proper feeding 
techniques, appropriate position during meals and quality of food. The result of this study shows by reducing neurodevelopmental problems and improving mother-child interaction development of a child with cerebral palsy, after feeding and seating intervention, significantly improved. So it is recommended that a simple home-based measure, like feeding and seating intervention, should be carried out under the guidance of Child Development Center run by developmental therapists with assistance from Pediatricians and Child psychologists in order to improve the development of children with cerebral palsy as well as quality of life.

\section{DISCLOSURE}

All the authors declared no competing interest.

\section{REFERENCES}

1. Gupte S. The shorttext book of pediatrics $10^{\text {th }}$ (silver jubilee) ed. New Delhi: Jaypee brothers Medical Publishers (P) Ltd. 2004; 17:336.

2. Tabib SMSB. Early childhood development: An emerging issue. Bangladesh medical journal. 2010; 39(1) 278-284

3. Evans J.L. et al. (2000) Early childhood counts: A programming guide on early childhood care for development. Washington D.C. The World Bank.

4. Yousafzal AK, Filteau S, Sheila WZ. Feeding difficulties in disabled children leads to malnutrition: experience in an Indian slum. Br. J Nutr. 2003; 90:1097-1106.

5. Morris S.E. and Klein M.D. (2000). Prefeeding skills. A comprehensive resource for mealtime development. $\left(2^{\text {nd }}\right.$ ed) .Tuscon, AZ: Therapy skill Builders.

6. Gisel EG, Patrick J. Identification of children with cerebral palsy unable to maintain a normal nutritional state. Lancet. 1988; 283-285.

7. Fishman LN, Bousvaros A. Gastrointestinal issue in the child with cerebral palsy. International seminars in pediatric Gastroenterology and nutrition. 1999; 8 (2): 1-15.

8. Gomez EM, Gupte S. Growth and development. In: Gupte S. The short text book of paediatrics $10^{\text {th }}$ ( Silver jubilee) ed. New Delhi: Jaypee Brothers Medical publishers (P) Ltd. 2004; 3:30

9. Reilly S, Skuse D, Polete X. Prevalence of feeding problems oral vey. J Pediatr. 1996; 129: 877-882.

10. Arvedson J.C. and Brodsky L. (1993). Pediatric swallowing and feeding assessment and management. San Diego, CA: Singular Publishing group.

11. Vik T, Skrove MS, Dellner H, Helland G. Feeding problems and growth disorders among children with cerebral palsy in south and north trondelag. TidsskrNorLaegeforen. 2001; 121(13): 157-164.

12. Ozturk M, Kutluhan S, Demicri S, Akhan G, Kisioglu AN, Akgum S, Haciahmetoglu H. Dietary assessment of children with cerebral palsy: Case control study in Isparta. Eastern journal of Medicine. 2004; 9(1):22-25.

13. Begum D, Akhter S, Khan NZ. Developemental outcomes of children with cerebral palsy after feeding and seating intervention, food quality changes and improvement in mother- child interaction. In: Zaman SS, Banu S, Khan NZ, Munir SZ, Ferdous S. Creating barrier free inclusive community and rights based society for children with disability. Bangladesh. 2005; 173-177.

14. Dr. HabibaJesmin. "Nutritional status in children wiyh cerebral palsy". 2009; 21-39.

15. Sullivan PB, Lambert B, Rose M, Ford Adams M, Jhonson A, Griffiths P. Prevalence and severity of feeding and nutritional problems in children with neurological impairment. Dev Med Child Neurol. 2000; 42(10): 674-680. 